\title{
Using thermodynamic cycles to study reactive intermediates
}

\author{
F. G. Bordwell,* A. V. Satish, Shizhong Zhang, and Xian-Man Zhang \\ Department of Chemistry, Northwestem University, 2145 Sheridan Road, \\ Evanston, IL 60208-3113 USA
}

\begin{abstract}
The observation of the near identity of the acidities in DMSO of benzoic acid, cyclohexane-1,3-dione enol (1), and tropolone (2) has provided experimental support for the importance of resonance in carboxylate ions. And the observation of the near identity of the homolytic bond dissociation enthalpies (BDEs) of the $\mathrm{O}-\mathrm{H}$ bond in 1 and the $\mathrm{C}-\mathrm{H}$ bond in $\mathrm{CH}_{3} \mathrm{COCH}_{2}-\mathrm{H}$, estimated by eq 3 , has provided experimental support for the importance of allylic resonance in radicals of the type $\mathrm{C}-\mathrm{C}=\mathrm{O} \longleftrightarrow \mathrm{C}=\mathrm{C}-\mathrm{O}^{\circ}$. The BDEs of the $\mathrm{O}-\mathrm{H}$ bonds in $t-\mathrm{Bu}_{2} \mathrm{C}=\mathrm{NOH}$ and $t-\mathrm{Bu}(1-\mathrm{Ad}) \mathrm{C}=\mathrm{NOH}$ ketoximes, estimated by eq 3 , of 83 and $81 \mathrm{kcal} / \mathrm{mol}$, respectively, are in excellent agreement with the values of 81 and $80 \mathrm{kcal} / \mathrm{mol}$, respectively, determined by a direct calorimetric method. The BDE of the $\mathrm{O}-\mathrm{H}$ bond in anti-benzaldoxime is $17 \mathrm{kcal} / \mathrm{mol}$ lower than that of the $\mathrm{O}-\mathrm{H}$ bond in acetaldoxime, indicating that the $\mathrm{PhCH}=\mathrm{NO}^{\circ}$ iminoxy radical is a $\pi$, rather than a $\sigma$, radical. The $15 \mathrm{kcal} / \mathrm{mol}$ lower $\mathrm{BDE}$ of the $\mathrm{O}-\mathrm{H}$ bond in $t-\mathrm{Bu}_{2} \mathrm{C}=\mathrm{NOH}$ ketoxime than that of the $\mathrm{Me}_{2} \mathrm{C}=\mathrm{NOH}$ ketoxime is attributed to relief of steric strain on homolytic cleavage. Relief of steric strain is believed to account also for the $8 \mathrm{kcal} / \mathrm{mol}$ lower BDE of the $\mathrm{O}-\mathrm{H}$ bond in 2,4,6-tri-t-butylphenol than that in phenol itself.
\end{abstract}

Introduction. Thermodynamic cycles have been used in our laboratory to study: (a) acidities of $\mathrm{HA}^{+\infty}$ radical cations (eq 1$)^{1}$ and $\mathrm{HA}^{2+}$ dications (eq 2$)^{2}$, and also to study (b) the homolytic bond disso-

$$
\begin{aligned}
& \mathrm{p} K_{\mathrm{HA}^{+\bullet}}=\mathrm{p} K_{\mathrm{HA}}+16.8\left[\mathrm{E}_{\mathrm{ox}}\left(\mathrm{A}^{*}\right)-\mathrm{E}_{\mathrm{ox}}(\mathrm{HA})\right] \\
& \mathrm{p} K_{\mathrm{HA}^{2+}}=\mathrm{p} K_{\mathrm{HA}^{+\bullet}}+16.8\left[\mathrm{E}_{\mathrm{ox}}\left(\mathrm{A}^{\bullet}\right)-\mathrm{E}_{\mathrm{ox}}\left(\mathrm{HA}^{+\bullet}\right)\right]
\end{aligned}
$$

ciation enthalpies (BDEs) of the acidic bonds in weak acids $\mathrm{HA}$ (eq 3 ), ${ }^{3}$ in $\mathrm{HA}^{+-}$radical cations (eq 4), ${ }^{4}$ and in $\mathrm{HA}^{\circ}-$ radical anions (eq 5$)^{5}$

$$
\begin{aligned}
& \mathrm{BDE}_{\mathrm{HA}}=1.37 \mathrm{p} K_{\mathrm{HA}}+23.1 \mathrm{E}_{\mathrm{ox}}\left(\mathrm{A}^{*}\right)+73.3 \mathrm{kcal} / \mathrm{mol} \\
& \mathrm{BDE}_{\mathrm{HA}^{+}}=\mathrm{BDE}_{\mathrm{HA}}+23.1\left[\mathrm{E}_{\mathrm{ox}}\left(\mathrm{A}^{\circ}\right)-\mathrm{E}_{\mathrm{ox}}(\mathrm{HA})\right] \\
& \mathrm{BDE}_{\mathrm{HA}}{ }^{-}=1.37 \mathrm{p} K_{\mathrm{HA}}+23.1 \mathrm{E}_{\mathrm{re}}(\mathrm{HA})+73.3 \mathrm{kcal} / \mathrm{mol}
\end{aligned}
$$

The simple, semiempirical method developed to estimated BDEs has been applied to the H-A bonds in hundreds of weak acids by means of eq 3. Information concerning the relative stabilities of anions, $\mathrm{A}^{-}$, has been obtained from the $\mathrm{p} K_{\mathrm{HA}}$ values, ${ }^{3.6}$ and information concerning the relative stabilities of the corresponding radicals, $\mathrm{A}^{*}$, has been obtained from the BDEs, relative to those of (a) the $\mathrm{C}-\mathrm{H}$ bond in $\mathrm{CH}_{3}-\mathrm{H}$, (b) the $\mathrm{N}-\mathrm{H}$ bond in $\mathrm{NH}_{2}-\mathrm{H}$, the O-H bond in $\mathrm{CH}_{3} \mathrm{O}-\mathrm{H}$, or like reference standards. (Henceforth, $\mathrm{kcal} / \mathrm{mol}$ will be abbreviated as kcal.) Agreement of BDEs estimated by eq 3 with gasphase BDEs for $\mathrm{C}-\mathrm{H}$ bonds ${ }^{7}$ to $\pm 3 \mathrm{kcal}$, or better, has been observed, ${ }^{3}$ and similar good agreement with literature BDEs for $\mathrm{N}-\mathrm{H}, \mathrm{O}-\mathrm{H}$, and $\mathrm{S}-\mathrm{H}$ bonds has also been observed in most instances. ${ }^{6}$ The $\triangle \mathrm{BDES}$ estimated for $\mathrm{H} \cdot \mathrm{A}$ bonds by eq 3 , relative to those of the reference standards, have been assumed to be equivalent to the relative radical stabilization energies (RSEs) of the corresponding $A^{\circ}$ radicals, following general practice. ${ }^{7.8}$ It should be kept in mind, however, that these RSEs may be subject to error because differences in ground state energies have not been taken into consideration. ${ }^{9}$ In the present paper, space limitations will restrict our discussion to an examination of information obtained from $\mathrm{p} K_{\mathrm{HA}}$ and $\mathrm{BDE}$ 
values of $\mathrm{O}-\mathrm{H}$ bonds in oxy-anions and the corresponding oxy-radicals. These data have provided new insights into the relative stabilities of the $\mathrm{O}-\mathrm{H}$ bonds in carboxylic acids, enols, oximes, and phenols, and into the structures of the corresponding radicals.

Is Resonance Important in Determining the Heterolytic and Homolytic BDEs of O-H Bonds in Carboxylic Acids and Enols? For many years delocalization of the negative charge in carboxylate ions, $\mathrm{RCO}_{2}^{-}$, and its absence in alkoxide ions, $\mathrm{RO}^{-}$, was accepted as the principal reason that carboxylic acids are more acidic than alcohols. But in 1986 it was suggested, on the basis of theoretical calculations, that the principal reason for the difference in these acidities resides in the strong polar interaction of the carbonyl group with the hydroxyl group in the undissociated carboxylic acid, which increases the positive potential of the proton and decreases the heterolytic BDEs of the O-H bonds. ${ }^{10}$ This conclusion has been challenged, however, ${ }^{11}$ and our observation of the near identity of the acidities in DMSO of benzoic acid, cyclohexane-1,3-dione enol $(\underline{l})$ and tropolone $(2)\left(\mathrm{p} K_{\mathrm{HA}}=11.2 \pm 0.2\right)$ has provided experimental<smiles>O=C(O)c1ccccc1</smiles><smiles>[O]c1cc(O)cc(O)c1</smiles>

1

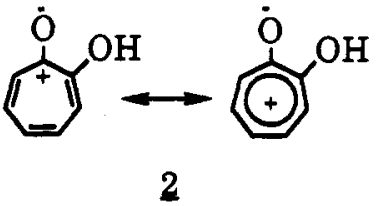

A progressive dispersal of positive charge does not

lead to a progressive decrease in acidity .

experimental evidence showing that dispersal of the positive charge over the C-1 and C-3 carbon atoms in $\underline{1}$ or the ring atoms of $\underline{2}$ does not have the expected acid-weakening effect resulting from a decrease in the positive potential at hydrogen. On the other hand, resonance involving the two oxygen and carbon skeletons in the anions derived from $\underline{1}$ and $\underline{2}$ provides stabilization comparable to that in the benzoate anion.

It is one of the tenets of the resonance theory that, when contributors of equal energy such as ' $\mathrm{O}-\mathrm{C}(\mathrm{R})=\mathrm{O} \longleftrightarrow \mathrm{O}=\mathrm{C}(\mathrm{R})-\mathrm{O}^{\circ}$ are possible, the energy of the hybrid species will be lowered appreciably. ${ }^{13}$ But, theoretical calculations indicate that resonance is unimportant in the formyl radical, $\mathrm{HCO}_{2}{ }^{\circ} \cdot{ }^{14}$ This conclusion appears to be supported by the near equality of the BDEs of the $\mathrm{O}-\mathrm{H}$ bonds in carboxylic acids and alcohols. ${ }^{7}$ ESR studies have suggested that resonance is also small in $\dot{C}-\mathrm{C}=\mathrm{O}$ type radicals. ${ }^{15}$ This conclusion is based on observations that in these radicals the spin densities reside primarily on carbon. ${ }^{15}$ For example, in the series $\mathrm{CH}_{3}{ }^{\circ}, \mathrm{MeCOCH}_{2}{ }^{\circ},(\mathrm{MeCO})_{2} \mathrm{CH}^{*}$, the ESR data show that the $\alpha_{\mathrm{CH}_{3}} \mathrm{H}$ values, which are estimated to be related to empirical spin densities, decrease only slightly from 23 to 19.3 to 18.6 gauss. ${ }^{15 \mathrm{c}}$ (Although the decrease in spin density on carbon has been judged to be small from the methyl radical to the acetonyl radical, ${ }^{15 \mathrm{c}}$ the BDE of the $\mathrm{C}-\mathrm{H}$ bond in acetone is $12 \mathrm{kcal}$ weaker than that in methane? In the tropolonyl radical the spin density resides to the extent of more than $75 \%$ on carbon, rather than on the two oxygen atoms, ${ }^{15 \mathrm{c}}$ and the 2 -cyclohexanonyl radical has been judged to have only about $30 \%$ allylic character with a small, but significant, contribution of the $\mathrm{C}=\mathrm{C}-\mathrm{O}^{\circ}$ to the resonance hybrid. ${ }^{15 \mathrm{~b}}$ The delocalization was believed to be sufficient, however, to account for the unusually high barriers observed in the $\mathrm{MeCOCH}_{2}{ }^{\circ}$ and $\mathrm{MeCOCMe}_{2}$ radicals $(9.4$ and $>10 \mathrm{kcal}$, respectively). ${ }^{15 \mathrm{~b}}$ The conclusion has also been drawn from ESR spectra, however, that resonances involving heteroatoms are unimportant in $\dot{\mathrm{C}}-\mathrm{C} \equiv \mathrm{N}$ and $\dot{\mathrm{C}}-\mathrm{NO}_{2}$ radicals, as well as in $\dot{\mathrm{C}} \cdot \mathrm{C}=\mathrm{O}$ radicals. ${ }^{15 \mathrm{c}}$ Nevertheless, introduction of a $\mathrm{C}=\mathrm{O}, \mathrm{C} \equiv \mathrm{N}$, or $\mathrm{NO}_{2}$ group for one of the hydrogen atoms in methane causes decreases in the BDEs of about 12,12 , and $7 \mathrm{kcal}$, respectively. ${ }^{16}$ And the BDE of the acidic $\mathrm{C}-\mathrm{H}$ bond in cyclohexanone is $17 \mathrm{kcal}$ lower than that of methane. ${ }^{17}$ The $\triangle \mathrm{BDEs}$ of the $\mathrm{O}-\mathrm{H}$ bond in 1 and 2 , relative to that in $\mathrm{Ph}(\mathrm{C}=\mathrm{O}) \mathrm{O}-\mathrm{H}$, or $\mathrm{CH}_{3} \mathrm{O}-\mathrm{H}(\sim 105 \mathrm{kcal})^{7}$ have also been found to be large, i.e., 13 and $17 \mathrm{kcal}$, respectively. ${ }^{12}$ The BDE data show, therefore, that delocalization of the odd electron both to and from oxygen in the $\mathrm{C}-\mathrm{C}=\mathrm{O} \longleftrightarrow \mathrm{C}=\mathrm{C}-\mathrm{O}^{\circ}$ is substantial.

We conclude that resonance in anions is important in determining heterolytic BDEs (acidities) of the $\mathrm{O}-\mathrm{H}$ bonds in carboxylic acids and enols, and that resonance is also important in determining homolytic BDEs of the $\mathrm{C}-\mathrm{H}$ bonds in ketones and the $\mathrm{O}-\mathrm{H}$ bonds in enols, but probably not in determining the BDEs of O-H bonds of carboxylic acids. ${ }^{18}$ 
Is Resonance Important in Determining the Heterolytic and Homolytic BDES of the $\mathrm{O}-\mathrm{H}$ Bonds in Oximes? The equilibrium acidities for the O-H bonds in 14 aldoximes and 19 ketoximes have been measured in DMSO solution, and the BDEs of the O-H bonds have been estimated using eq $3 .{ }^{6 \mathrm{c}}$ The $\mathrm{p} K_{\mathrm{HA}}$ of acetaldoxime was found to be 28.3 in DMSO, i.e., near to that of methanol in DMSO ( $\mathrm{p} K_{\mathrm{HA}}$ $=29$ ), suggesting that $\mathrm{C}=\mathrm{N}-\mathrm{O}^{-} \longleftrightarrow \overline{\mathrm{C}}-\mathrm{N}=\mathrm{O}$ is of little importance, if we accept the acidity of $\mathrm{CH}_{3} \mathrm{OH}$ to be a good model for a parent. The $\mathrm{p} K_{\mathrm{HA}}$ values of the $\mathrm{O}-\mathrm{H}$ bonds in syn- and anti-benzaldoximes in DMSO are each $8 \mathrm{p} K_{\mathrm{HA}}$ units $(9.6 \mathrm{kcal})$ more acidic than that of acetaldoxime. Here, delocalization of the negative charge from oxygen to the phenyl ring is the likely cause of these enhanced acidities.

The iminoxy radicals derived by oxidation of oximes have been the subject of ESR studies in several laboratories. The consensus of opinion arrived at is that iminoxy radicals are best represented as hybrids of resonance contributors $3 \mathrm{a}$ and $\underline{3 \mathrm{~b}} .{ }^{19}$ The $\pi$-type orbital representing the three-electron bond

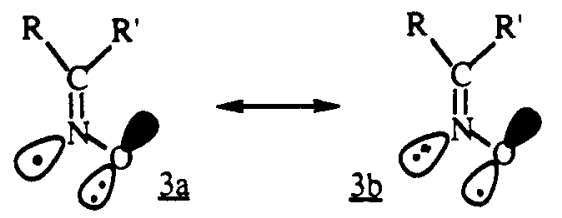

is believed to lie in the nodal plane of the $\mathrm{C}=\mathrm{N} \pi$ bond, which requires it to be orthogonal to the molecular $\pi$ system. For this reason the radicals have been described as $\sigma$-radicals, rather than $\pi$-radicals. ESR evidence for the assignment of iminoxy radicals as $\sigma$ radicals was said to be apparent from all of the data in a paper in which the ESR spectra of 28 iminoxy radicals was reported. ${ }^{19 \mathrm{C}}$

The BDEs of the $\mathrm{O}-\mathrm{H}$ bonds in acetaldoxime and propionaldoxime are each estimated to be 98 kcal. ${ }^{6 \mathrm{c}}$ The $\triangle \mathrm{BDEs}$ relative to the literature BDE of the $\mathrm{O}-\mathrm{H}$ bonds in alcohols $\left(\sim 105 \mathrm{kcal}^{7}\right)$ suggest an RSE of $7 \mathrm{kcal}$ for $\mathrm{RCH}=\mathrm{NO}^{\circ}$ radicals. (The BDE of the $\mathrm{H}-\mathrm{O}$ bond in $\mathrm{H}_{2} \mathrm{NOH}$ would be a better model, but is not yet known.) The BDEs of anti- and syn-benzaldoxime, are $9-11 \mathrm{kcal}$ lower than that of acetaldoxime or propionaldoxime, which indicates that these iminoxyl radicals are behaving as $\pi$ radicals with extensive delocalization of the odd electron into the benzene rings, contrary to the conclusions drawn from the ESR studies.

Two paths can be visualized by which an electron can be removed from the oxygen atom of an oxime anion (Scheme I). If the electron is removed from the $\rho_{x}$ orbital that is in the same plane as the lone pair on nitrogen (path $a$ ), a 3-electron $\pi$-type $(\sigma)$ bond of the type described by Symons et al. ${ }^{19}$ will be formed. On the other hand, if the electron is removed from a $\rho_{y}$ orbital that is perpendicular to the $\rho_{\mathrm{x}}$ orbital the odd electron can be stabilized by delocalization to carbon (path $b$ ). Path $b$ will be favored when a group capable of delocalizing an odd electron, such as a phenyl group, is present on the $\mathrm{sp}^{2}$ carbon atom in the oxime. Path $b$ should also be favored by an increase in the bulk of $R^{\prime}$, as will become apparent later.
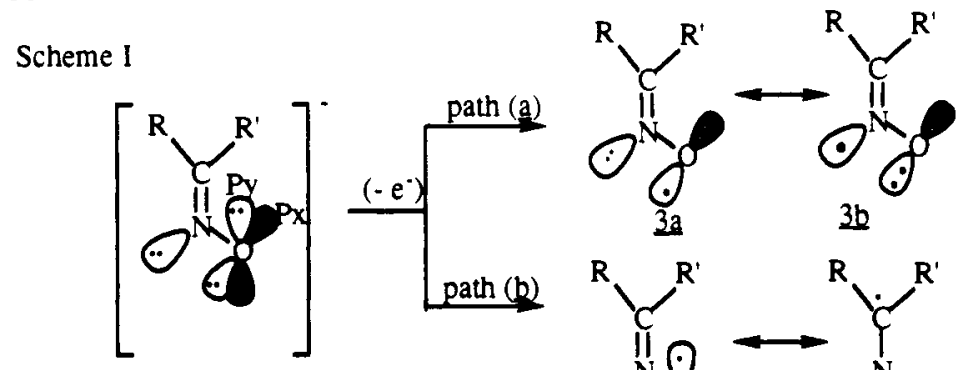

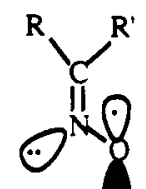

$4 \mathrm{a}$

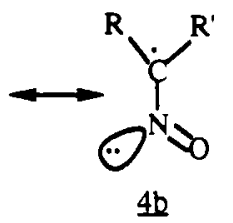

The BDEs of the $\mathrm{O}-\mathrm{H}$ bonds in $t-\mathrm{Bu}{ }_{2} \mathrm{C}=\mathrm{NOH}$ and $t-\mathrm{Bu}(1-\mathrm{Ad}) \mathrm{C}=\mathrm{NOH}$ ketoximes have been determined to be 80.9 and $80.0 \mathrm{kcal}$, respectively, in benzene by a direct calorimetric method that is applicable only when the corresponding radicals are stable at room temperature for several hours. ${ }^{20}$ The BDEs reported for these ketoximes, which bear two large alkyl groups ( $t$-butyl, 1 -adamantyl), contrast sharply with the $\mathrm{BDE}$ of $95.8 \mathrm{kcal}$ for the $\mathrm{O}-\mathrm{H}$ bonds in the ketoxime, $\mathrm{Me}_{2} \mathrm{C}=\mathrm{NOH}$, estimated using eq $3{ }^{6 \mathrm{c}}$ 
It was clear that, either our method of estimating BDEs was not reliable for these compounds, or that the increase in the size of the alkyl groups in these oximes has caused a dramatic decrease in BDE. Synthesis of $t-\mathrm{Bu}_{2} \mathrm{C}=\mathrm{NOH}$ and $t-\mathrm{Bu}(1-\mathrm{Ad}) \mathrm{C}=\mathrm{NOH}$ and estimation of the BDEs from their $\mathrm{p} K_{\mathrm{HA}}$ values and the $E_{o x}\left(A^{*}\right)$ values in DMSO of their conjugate bases using eq 3 gave $B D E$ values of 83.1 and 81.1 $\mathrm{kcal}$, respectively), ${ }^{21}$ which are in remarkably good agreement with those of Mahoney et al. ${ }^{20}$ considering the difference in methods and experimental conditions. Furthermore, the $\mathrm{p} K_{\mathrm{HA}}$ values for the $\mathrm{O}-\mathrm{H}$ bonds in these two oximes should be accurate at least to within $0.2 \mathrm{kcal}$, and the (reversible) $E_{0 x}\left(A^{*}\right)$ values for these two oxime anions should be accurate $\pm 1.2 \mathrm{kcal}$, so the BDEs estimated by eq 3 should be accurate to $\pm 2 \mathrm{kcal}$, or better.

Estimates of BDEs of the $\mathrm{O} \cdot \mathrm{H}$ bonds for additional ketoximes, relative to that of the $\mathrm{O}-\mathrm{H}$ bond in $\mathrm{Me}_{2} \mathrm{C}=\mathrm{NOH}$, by eq 3 showed that the $\mathrm{O}-\mathrm{H}$ bonds were weakened progressively by 3.5 to 5.3 to 5.7 to $6.1 \mathrm{kcal}$ for the oximes of diethyl ketone, pinacolone, 4-t-butylcyclohexanone, and cyclohexanone, respectively. The $\mathrm{O}-\mathrm{H}$ bonds in the oximes derived from camphor, norcamphor, and diisopropyl ketone were weakened further (by $6.8,9.4$, and $8.7 \mathrm{kcal}$, respectively). And there is substantial further weakening by 12.7 and $14.7 \mathrm{kcal}$, respectively, for the $\mathrm{BDEs}$ of the $\mathrm{O}-\mathrm{H}$ bonds in $t-\mathrm{Bu}_{2} \mathrm{C}=\mathrm{NOH}$ and $t-\mathrm{Bu}(1-\mathrm{Ad}) \mathrm{C}=\mathrm{NOH}$. Examination of the $\mathrm{p} K_{\mathrm{HA}}$ and $\mathrm{E}_{\mathrm{ox}}\left(\mathrm{A}^{*}\right)$ values shows that the progressive increase in the size of $\triangle B D E$ values is caused primarily by a progressive shift of $E_{0 x}\left(A^{-}\right)$values to more negative values; the $\mathrm{p} K_{\mathrm{HA}}$ values remain relatively constant. It would appear that there is a progressive increase in the ground state energies of the oxy-anions as the size of the alkyl groups increase due to progressive increases in the non-bonded interactions between $\mathrm{R}^{\prime}$ and the $\mathrm{OH}$ group in the oxime (Scheme I). The increase in steric strain in the ground state with increasing alkyl size is made apparent by a comparison of the bond lengths and bond angles in $\mathrm{Me}_{2} \mathrm{C}=\mathrm{NOH}$ and $t \cdot \mathrm{Bu}_{2} \mathrm{C}=\mathrm{NOH}$ as revealed by $\mathrm{X}$-ray crystal structures. ${ }^{21}$ This analysis suggests that the increase in strain weakens the $\mathrm{O}-\mathrm{H}$ bond and encourages bond cleavage, which is accompanied by the lengthening and rotation of the $\mathrm{C}-\mathrm{N}$ bond to minimize the steric interaction. The progressive increase in the size of the $R^{\prime}$ group results in a progressive decrease in $\mathrm{BDE}$.

There appears to be little or no relationship between $a_{\mathrm{N}}$ or $a_{\mathrm{H}}$ ESR coupling constants of iminoxy radicals and the $\mathrm{BDE}$ values of the $\mathrm{O}-\mathrm{H}$ bonds in the corresponding oximes. For example, all of the $a_{\mathrm{N}}$ coupling constants of the iminoxy radicals derived from the 28 ketoximes studied by Gilbert and Nor$\operatorname{man}^{19 \mathrm{c}}$ fall in the range of 28-32 gauss, whereas the BDEs for the $\mathrm{O}-\mathrm{H}$ bonds in our study cover a range of $14 \mathrm{kcal}$.

Acidities and BDEs of 4-Substituted-2,6-di-t-butyl Phenols. Introduction of either a 4-Me or 4-t-butyl group into phenol causes a decrease in acidity of about $1 \mathrm{p} K_{\mathrm{HA}}$ unit, presumably due to acidweakening steric inhibition of solvation in the anions countered to some extent by an acid-strengthening puarizability effect. Introduction of $2,6-(t-\mathrm{Bu})_{2}$ or $2,4,6-(t-\mathrm{Bu})_{3}$ groups into phenol increases the acidity by 0.7 and $0.2 \mathrm{p} K_{\mathrm{HA}}$ units, respectively. ${ }^{22}$ Here, the acid-strengthening polarizability effects of the bulky $t$-butyl groups on the anions when combined with the increased steric strains they introduce on the undissociated acid are evidently sufficient to overshadow steric inhibition of solvation in the anions. The steric strains are relieved by loss of a proton, thus providing an acid-strengthening effect. A consideration of the effects of 2,6-(t-Bu $)_{2}$ and $2,4,6-(t-\mathrm{Bu})_{3}$ groups on the BDEs of these substituted phenols does indeed point to the presence of steric strains, as will be brought out shortly.

2,4,6-Trisubstituted phenols such as $2,4,6-(t-\mathrm{Bu})_{3} \mathrm{C}_{6} \mathrm{H}_{2} \mathrm{OH}(5)$ and $\alpha$-tocopherol (6; vitamin E) have aroused considerable interest because of their antioxidant properties. Loss of a hydrogen atom from $\underline{5}$ gives a persistent radical that is stable for several hours, and the BDE of the O-H bond in $\underline{5}$ has been determined to be $81.2 \mathrm{kcal}$ by a direct calorimetric method. ${ }^{20}$ That of $\underline{6}$ has been determined to be 80.4 kcal by a kinetic study and a Polanyi-type correlation of rates of hydrogen atom abstractions versus BDEs. ${ }^{23}$ Application of eq 3 to estimate the BDEs of the O-H bonds in $\underline{6}$ and $\underline{5}$ gave BDEs of 81.7 and $80.3 \mathrm{kcal}$, respectively, ${ }^{24}$ in excellent agreement with those determined by the earlier methods. Estimates of BDEs of the O-H bonds in 4-G-2,6- $(t-\mathrm{Bu})_{2} \mathrm{C}_{6} \mathrm{H}_{2} \mathrm{OH}$ phenols showed that the BDEs of the $\mathrm{H}-\mathrm{O}$ bonds in these phenols had been decreased, relative to that of phenol itself by the amounts (kcal shown in parentheses): $\mathrm{MeOCO}(6.2), \mathrm{H}(7.8), t$-Bu (8.2), $\mathrm{Me}$ (10.4), Et (10.4), or $\mathrm{MeO}$ (10.9). 
Rotation of the OH or $t$-Bu groups in $\underline{5}$ is severely hindered, ${ }^{25}$ but the $t$-butyl groups in the corresponding radical are freely rotating. ${ }^{26}$ The heat of the isodesmic reaction between $\underline{5}$ and benzene to give $1,3,5-(t-\mathrm{Bu})_{3} \mathrm{C}_{6} \mathrm{H}_{3}$ and phenol has been calculated to be $-8.2 \mathrm{kcal}^{27}$

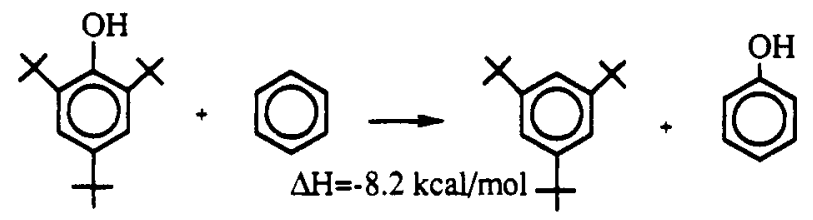

It seems likely, then, that the $8.2 \mathrm{kcal}$ weaker $\mathrm{O}-\mathrm{H}$ bond in $\underline{5}$ than that in phenol, estimated by eq 3 , may be due entirely to a higher ground state energy in $\underline{5}$ caused by steric strains that are relieved by homolytic cleavage of the $\mathrm{O}-\mathrm{H}$ bond. The somewhat weaker $\mathrm{O}-\mathrm{H}$ bonds in $4-\mathrm{G}-2,6-(t-\mathrm{Bu})_{2} \mathrm{C}_{6} \mathrm{H}_{3} \mathrm{OH}$ phenols when $\mathrm{G}$ is $\mathrm{Me}, \mathrm{Et}$, or $\mathrm{MeO}$ can be attributed to release of strain accompanying $\mathrm{O}-\mathrm{H}$ bond cleavage, combined with additional stabilizing effects of the $\mathrm{Me}$, Et, or $\mathrm{MeO}$ groups on the radicals being formed.

Acknowledgments. This research was supported by a grant from the donors of the Petroleum Research Fund administered by the American Chemical Society and by the National Science Foundation.

\section{REFERENCES AND NOTES}

1. F. G. Bordwell and M. J. Bausch. J. Am. Chem. Soc. 108, 2473 (1986),

2. X.-M. Zhang and F. G. Bordwell. J. Org. Chem. 57, 4163 (1992).

3. F. G. Bordwell, J.-P. Cheng, G.-Z. Ji, A. V. Satish and X.-M. Zhang. J. Am. Chem. Soc. 113, 9790 (1991), and references cited therein.

4. X.-M. Zhang and F. G. Bordwell. J. Am. Chem. Soc. 114, 9787 (1992).

5. X.-M. Zhang and F. G. Bordwell. J. Am. Chem. Soc. 115, 904 (1994)

6. (a) F. G. Bordwell, J. A. Harrelson, Jr. and T.-Y. Lynch. J. Org. Chem. 55, 3337 (1990). (b) F. G. Bordwell, X.-M. Zhang and J.-P. Cheng. J. Org. Chem. 56, 3216 (1991). (c) F. G. Bordwell and G.-Z. Ji. J. Am. Chem. Soc. 113, 8399 (1991). (d) F. G. Bordwell, D. L. Singer and A. V. Satish. J. Am. Chem. Soc. 115, 3543 (1993). (e) F. G. Bordwell, X.-M. Zhang and J.-P. Cheng. J. Org. Chem. 58, 6410 (1993).

7. (a) D. F. McMillen and D. M. Golden. Annu. Rev. Phys. Chem. 33, 473 (1982). (b) J. L. Holmes, F. R. Lossing and J. K. Terlouw. J. Am. Chem. Soc. 108, 1086 (1986).

8. (a) H. E. O'Neal and S. W. Benson, Free Radicals, J. J. Kochi, Ed., Wiley, New York (1973).

(b) D. C. Nonhebel and J. C. Walton. Free Radical Chemistry, Cambridge University Press, Cambridge, U.K., p. 102 (1974). (c) D. Griller and K. U. Ingold. Acc. Chem. Res. 13, 193 (1980).

9. K. B. Clark and D. D. M. Wayner. J. Am. Chem. Soc. 113, 9363 (1991), and references cited therein.

10. M. R. F. Siggel and T. D. Thomas. J. Am. Chem. Soc. 108, 4360 (1986). M. R. F. Siggel, A. Streitwieser Jr. and T. D. Thomas. J. Am. Chem. Soc. 110, 8022 (1988).

11. (a) O. Exner. J. Org. Chem. 53, 1810 (1988). (b) M. J. S. Dewar and K. L. Krull. J. Chem. Soc. Chem. Commun. 333 (1990). (c) R. W Taft, I. A. Koppel, R. D. Topsom and F. Anvia. J. Am. Chem. Soc. 112, 2047 (1990).

12. F. G. Bordweil and A. V. Satish J. Am. Chem. Soc. in press (1994).

13. C. W. Wheland. Resonance in Organic Chemistry, Wiley, N.Y. (1955).

14. D. Feller, E. S. Huyser, W. T. Borden and E. R. Davidson. J. Am. Chem. Soc. 105, 1459 (1983).

D. Feller, E. R. Davidson and W. T. Borden. J. Am. Chem. Soc. 106, 2513 (1984).

15. (a) O. H. Griffith. J. Chem. Phys. 42, 2655 (1965). (b) D. M. Camaioni, H. F. Walter and D. W. Pratt. J. Am. Chem. Soc. 95, 4057 (1973). (c) G. A. Russell and J. Lokensgard J. Am. Chem. Soc. 89, 5059 (1967).

16. F. G. Bordwell, X.-M. Zhang and M. S. Alnajjar. J. Am. Chem. Soc. 114, 7623 (1992).

17. F. G. Bordwell and J. A. Harrelson, Jr. Can. J. Chem. 68, 1714 (1990).

18. Combining the $\mathrm{p} K_{\mathrm{HA}}$ value of 29 for $\mathrm{MeOH}$ with a preliminary $\mathrm{E}_{\mathrm{ox}}\left(\mathrm{A}^{-}\right)$value for $\mathrm{MeO}^{-}$ion in DMSO has given a BDE of $115 \mathrm{kcal}$ for the $\mathrm{H}-\mathrm{O}$ bond in $\mathrm{CH}_{3} \mathrm{OH}$, which approaches that for the $\mathrm{O}-\mathrm{H}$ bond in $\mathrm{HOH}\left(119 \mathrm{kcal}^{7}\right)$ and $10 \mathrm{kcal}$ higher than that in benzoic acid. ${ }^{7}$ 
19. (a) M. R. C. Symons. J. Chem. Soc. 2276 (1965). (b) M. Behoux, H. Lemaire and A. Rassat. Bull. Soc. Chim. France 1985 (1964). (c) B. D. Gilbert and R. O. C. Norman. J. Chem. Soc. (B) 86 (1966).

20. L. R. Mahoney, F. C. Ferris and M. A. DaRooge. J. Am. Chem. Soc. 91, 3883 (1969).

21. F. G. Bordwell and S. Zhang. J. Am. Chem. Soc. submitted (1994).

22. F. G. Bordwell and J.-P. Cheng. J. Am. Chem. Soc. 113, 1736 (1991).

23. G. W. Bunton, T. Duba, E. J. Gabe, L. Hughes, F. L. Lee and K. U. Ingold. J. Am. Chem. Soc. 95, 8610 (1973).

24. F. G. Bordwell and X.-M. Zhang. J. Am. Chem. Soc. submitted (1994).

25. M. Davis and L. Meakins. J. Chem. Phys. 26, 1580 (1956).

26. K. Mukai, H. Nishiguchi, K. Ishizu, Y. Deguchi and H. Takaki. Bull. Chem. Soc. Jpn. 40, 2731 (1967).

27. L. R. Mahoney, G. D. Mendenhall, L. Prasad and K. U. Ingold. J. Am. Chem. Soc. 95, 8610 (1973). 